\title{
O corpo como cogito: um cinema contemporâneo à luz de Merleau-Ponty
}

\section{Julio Bezerra}

\section{Resumo}

Este ensaio nasce de uma constatação: 0 cinema contemporâneo está marcado por uma espécie de nova transnacional. Um cinema que se acha intimamente ligado a uma mudança de olhar lançado ao corpo. 0 corpo como reflexo, como metáfora, como lugar experimental de representação. A nossa hipótese é a de que a fenomenologia de MerleauPonty nos fornece valiosos instrumentos para ampliarmos a reflexão sobre um cinema que explora uma relação corporal com o mundo. 0 nosso objetivo é discutir essas questões em breves análises de três cineastas contemporâneos: Tsai Ming-Liang, A. Weerasethakul e Karim Ainouz.

\section{Palavras-chave}

Cinema contemporâneo. Corpo.

Fenomenologia. Merleau-Ponty.
Julio Bezerra I juliocarlosbezerra@hotmail.com

Doutorando em Comunicação pelo PPGCOM/UFF. Mestre em Comunicação e Cultura pela ECO-UFRJ (2008), com especialização em Cinema Documentário pela FGV (2006), e possui graduação em Comunicação pela PUC-Rio (2003). Atualmente é repórter e crítico de cinema na Revista de Cinema (www.revistadecinema.com.br), e editor de texto da Revista de História da Biblioteca Nacional (www.revistadehistoria.com.br). Escreve sobre cinema para a Cinética (www.revistacinetica.com.br) e mantém um blogue sobre a sétima arte, Kinos (www.cinekinos.blogspot.com).

\section{Introdução}

Algo acontece no cinema contemporâneo. Uma espécie de "nova onda transnacional", única desde meados dos anos 60, vem levando a sétima arte adiante. É curioso atentarmos para o fato de que realizadores tão diferentes como Claire Denis, Hou-Hsiao-Hsien, Tsai Ming-Liang, Edward Yang, Karim Aïnouz, Lucrecia Martel, Gus Van Sant, Pedro Costa, Apichatpong Weerasethakul, Abel Ferrara, entre outros, apresentem uma mesma sensibilidade em relação aos valores do mundo e do cinema. Essa sensibilidade diz respeito a um outro paradigma, diverso daquele que estabelece 0 hiper-realismo ou 0 esgarçamento das fronteiras da tecnologia que tanto marcaram as décadas de 80 e 90.

Diverso também do paradigma predominante no cinema moderno dos anos 60 e 70 :

Se o cinema moderno rompeu o pacto de confiança entre o espectador e a imagem, dando origem a uma geração à qual era necessário refletir sobre a linguagem para refletir sobre 0 mundo, alguns caminhos do vasto e poliforme 'cinema contemporâneo' nos indicam uma volta à crença na imagem. Como uma afirmação de 
crença no mundo. A imagem cinematográfica como mediadora privilegiada entre o espectador, entregue ao prazer de se ir ao seu encontro, e 0 mundo, físico e vivo. Entregues às imagens que pulsam, podemos então pulsar junto com elas e senti-las em toda sua intensidade (M0NASSA, 2004).

Se Jean-Luc Godard (Acossado) apostava, entre outros elementos, nos falsos raccords, nos jump-cuts, nas citações e em um tipo diferente de atuação, para contar suas histórias e sacudir o espectador; se, para ele, a imagem era uma coisa que se desmonta e ou se remonta, Claire Denis ou Lisandro Alonso caminham em outra direção: a experimentação de um tempo outro, que não é indeterminado, nem exatamente confuso ${ }^{1}$. A aposta agora é em blocos sensoriais, fragmentos soltos de um real sem peso. $\operatorname{Em} O$ intruso (2004), por exemplo, Denis multiplica elipses sem assinalá-las como tais, jamais sublinha quais sequências são "reais" e quais são sonhadas, e torna a compreensão deste longa algo ambíguo e talvez até aleatório. A impressão é a de que a cineasta deixa seus planos à mercê das sensações. E, assim, até mesmo as noções de confrontação dramática e de mise-en-scène ${ }^{2}$ começam a fazer pouco sentido.

Este cinema (que começa dar as caras em finais da década de 90) narra um estado de coisas à flor da pele e chama o espectador para mais perto. Filmes como Mal dos trópicos (2004), O intruso (2004), Last days (2005) e Juventude em marcha (2006) parecem nos exigir uma espécie de virgindade cinematográfica. Para o espectador, o que se estabelece é uma relação com o filme não mais como cognitiva e, sim, sensorial.

0 conteúdo simbólico da obra, no campo intelectivo, passa a ser uma questão de segunda ordem. Não se trata, no entanto, de afirmar simplesmente o primado da sensibilidade em detrimento das funções narrativas do filme. 0 que se reivindica é o reconhecimento, no âmbito da teoria do cinema, de um sentido sensível que se não é superior ao sentido lógico a este é anterior.

Dessa maneira, o que mais desejamos explorar desse cinema é seu interesse pela pele, por um realismo mais centrado no fenômeno da experiência, e por uma relação mais física com a câmera. Pois uma das maiores pulsões desse cinema é o encantamento físico do corpo. A produção cinematográfica mais contemporânea se acha intimamente ligada a uma mudança de olhar lançado ao corpo. 0 corpo como reflexo, como metáfora, como lugar experimental de representação.

Como nos alertam Wilton Garcia e Bernardette Lyra (2002), o cinema foi o primeiro invento tecnológico a dar movimento e vida às imagens,

0 que não quer dizer que alguns cineastas "modernos", como, por exemplo, Michelangelo Antonioni e Robert Bresson, apresentem uma série de afinidades em relação aos realizadores contemporâneos. E mesmo um cineasta tão marcadamente moderno como Godard dirigiu longas como Je vous salue Marie (1985), que também se aproxima de muito do que vem sendo feito nesses últimos anos.

Ver Aumont (2008). 
criando corpos sem carne. Ao construir espaços de luz e sombra, escuridão e visibilidade, 0 texto cinematográfico transforma o corpo humano e o corpo das coisas numa geometria de formas, superfícies, volumes e texturas. Do chamado primeiro cinema, às estéticas pretensamente naturalistas ou aos gêneros despudoradamente fantasiosos, há sempre um desejo pelo corpóreo. Corpóreo, como sublinha José Gil (2001), diz respeito à essência ou à natureza dos corpos ou dos estados corporais, relacionando-se a tudo que preencha o espaço e se movimente, mas que, ao mesmo tempo, situe o homem como um ser no mundo.

No cinema contemporâneo, no entanto, 0 termo toma uma interpretação simbólica, passando a traduzir um corpo expressivo, 0 qual preenche 0 espaço determinado, de modo a comprometê-lo com seus significados. Não se trata de percebermos um corpo construído por intermédio dos artifícios de edição de imagens, propiciado pelas muitas ferramentas do meio digital, mas sim identificarmos um corpo que se torna o sujeito do discurso. Um corpo crítico, político, que questiona a sua própria condição, e que se desconstrói à nossa frente. Essa nova apropriação do corpo pelo cinema não parece mais baseada na intervenção da tecnologia no corpo orgânico (pensemos em Paul Verhoeven), nem na concepção do corpo como um sistema eletrônico, originado no poder da engenharia computacional (como em grande parte do cinema de David Cronemberg).
0 mundo descrito em filmes como Madame Satã (2002) e $O$ pântano (2001) é, antes de mais nada, um mundo físico, em seus interstícios, em seu movimento microscópico e permanente, que se confunde, se identifica com 0 aspecto sensorial dos personagens, corpos que interagem com a paisagem, com os corpos da natureza, animados ou inanimados, integrados. 0 corpo assume uma função híbrida, torna-se um campo de passagens entre elementos orgânicos e sintéticos, uma estrutura fluida e dinâmica.

0 corpo passa a ser não mais uma unidade, mas um elo entre os corpos, entre os espaços e os movimentos, de modo a se criarem corpos virtuais, extensões do corpo físico. 0 cinema de fluxo lida com uma conexão com a natureza, com uma noção de fluxo e variação de energias, de forças, de vibrações e isso tem a ver com 0 modo como os corpos visíveis ou invisíveis da natureza são estimulados, como eles sofrem interferência do meio (MARQUES, 2008).

Desta vez, o corpo é o "ancoradouro do ser", é um modo de relação com o mundo. Este cinema contemporâneo privilegia o corpo como começo e fim expressivo e nos traz personagens tomados pela percepção. É o caso, por exemplo, dos personagens de filmes como 0 rio (1997) e $O$ quarto de Vanda (2000), situados em uma espécie de dimensão ingênua e natural do mundo. É um cinema que expressa ou denota uma dimensão imediata, perceptual, não conceitual (mas nem por isso caótica ou desarticulada) da experiência, que deriva fundamentalmente da imersão de nosso corpo no mundo através dos sentidos. 
Este movimento de recuperação de uma dimensão pré-lógica ou pré-predicativa da experiência e de sua ambiguidade e indeterminação encontra todo um arcabouço teórico na fenomenologia de Merleau-Ponty. Na teoria do pensador francês, o problema das relações entre a alma e o corpo é exposto em novos termos. Merleau-Ponty tenta fundar uma fenomenologia particular que não parta da consciência, mas sim do corpo definido de outra maneira. À psicologia da forma, Merleau-Ponty acrescenta os estudos de Husserl e a noção de "corpo próprio". Sua originalidade consiste em combater o empirismo e o intelectualismo ao mesmo tempo. Os pontos de vista filosóficos e científicos são igualmente rejeitados. MerleauPonty declara que se deve partir de uma consciência situada e concreta.

Para Merleau-Ponty, o conhecimento não é uma atividade da mente ou da razão, descoladas do corpo. É o corpo, em sua inscrição imediata no mundo, e por sua ação perceptivamente guiada, que nos possibilita uma primeira forma de organização da experiência, ainda não mediada pelas significações que a linguagem opera, mas carregada de discriminações, referências, nuances, preferências, rejeições etc.

0 corpo é nosso meio geral de ter um mundo. Ora ele se limita aos gestos necessários à conservação da vida e, correlativamente, põe em torno de nós um mundo biológico; ora, brincando com seus primeiros gestos e passando de seu sentido próprio a um sentido figurado, ele manifesta através deles um novo núcleo de significação: é o caso dos hábitos motores da dança. Ora enfim a significação visada não pode ser alcançada pelos meios naturais do corpo; é preciso então que ele construa um instrumento, e ele projeta em torno de um mundo cultural (MERLEAUPONTY, 1994, p. 203).

A fenomenologia de Merleau-Ponty nos fornece então valiosos instrumentos para ampliarmos a reflexão sobre um cinema que parece denunciar a falência da dicotomia interior/exterior, que explora o fenômeno da percepção como uma atividade que marca uma relação corporal com o mundo. Nossa proposta é levar esse diálogo adiante por meio de uma breve análise do cinema de três autores: Tsai Ming-Liang, Apichatpong Weerasethakul e Karim Ainouz. De maneiras diferentes, os três se apropriam do corpo como forma de comunicação vital com o mundo e revelam curiosas afinidades com o pensamento de Merleau-Ponty.

\section{Tsai Ming-Liang}

Num olhar sobre as consequências sociais e comportamentais da modernização asiática, o cinema de Taiwan tem revelado cineastas da maior importância. Tsai Ming-liang é um deles, e figura de maneira peculiar e solitária nesta cinematografia. É resultado de uma estranha mistura de uma fascinação clínica pela observação/contemplação com uma mitologia toda particular, na qual o convívio social somente intensifica a solidão, onde não há comunicação possível. Tsai não parece pensar 
o conflito entre tradição e modernidade, mas constrói um olhar distanciado, dilatado temporalmente, que mescla ironia e angústia, comédia e tragédia, consciência e hipnose.

Talvez o mais interessante da obra truffautiana do Tsai Ming-liang seja o fato de nos tornarmos sempre íntimos de seus personagens. Seus gestos mais banais, sua vida mais desinteressante nos são jogados no colo. Mesclando voyeurismo e consciência crítica, os filmes descobrem seus personagens em suas atitudes e manias - tão pequenas e banais quanto suas vidas. É o cinema dos pequenos instantes, das pequenas ideias, de uma desdivinização do mundo. 0 rio é um bom exemplo. Em sua primeira metade, o filme segue uma lógica muito precisa de construção, de exposição das personagens. Depois que Hsiao-kang (ou Kang-sheng) se lava no hotel, sua amiga chega trazendo sua roupa limpa e alguma comida, para logo depois ambos se engajarem nos afazeres sexuais. Um corte interrompe a ação e nos leva a um espaço desconhecido, onde um corpo masculino nu envolvido em uma toalha rejeita as carícias de um outro homem. Ele dirige-se à sala de banhos, lava-se, e vai para casa ocupar-se de seus afazeres domésticos para depois ser visto fazendo um lanche no McDonald's de um shopping. 0 filme segue assim à risca uma técnica de caracterização física que fez lembrar a alguns críticos, não sem razão, 0 cinema de Buster Keaton e Jacques Tati.
Lembremos também de Merleau-Ponty, que diz que 0 mundo é mais velho do que a consciência e do que nós: "não é preciso perguntar-se se nós percebemos verdadeiramente um mundo, é preciso dizer, ao contrário: 0 mundo é aquilo que percebemos" (MERLEAU-PONTY, 1994, p. 1314). Em sua obra, a invocação de um irrefletido e de um "cogito tácito", anteriores a toda tese posta pelo intelecto, visa encontrar na própria experiência, no vivido, um meio para sair do recinto fechado da consciência de maneira a realizar efetivamente o projeto husserliano de "volta às próprias coisas".

Este resgate está na pauta do cinema de Tsai Ming-Liang. Um filme como $O$ Rio se baseia em uma fé perceptiva no mundo, em uma adesão à experiência vivida pelos personagens. Hsiao-kang (modelo-protagonista-corpo) executa ações quase simbólicas de um estado de coisas. E os planos são menos uma unidade de ação e dramaturgia do que um exercício do olhar. Não há mise-enscène, ao menos no sentido de disposição do plano como quadro. A atividade de filmar se torna uma ferramenta de percepção da presença dos corpos no espaço. Para Ming-liang, em perfeita sintonia com Merleau-Ponty, a melhor maneira de se entender o humano é olhar como o homem se engaja na prática de sua existência. A tomada se torna um campo de observação fenomenológica.

\section{Karim Aïnouz}

Karim Aïnouz faz uma versão pé-sujo do cinema do Tsai Ming Liang. Em seus filmes, (incluindo 
os curtas Seams e Paixão nacional) temos sempre personagens presos a situações íntimas insustentáveis. Criaturas de uma dignidade nada cordial e imunes às adversidades que 0 mundo lhes impõe como condição de existência. E é sempre o cinema, como um ato político e de fé, que será responsável por uma possível experiência de transformação para os seus personagens. Em Karim, o cinema é uma experiência (estética e política) transformadora. Sua lógica reside na crença de que toda revolução começa e termina no indivíduo.

Em Madame Satã , o personagem não existe apenas na medida em que ele conta uma história. Muito pelo contrário. 0 cinema de Karim é assumidamente "mundano". Essa mundanidade de seus personagens está intimamente ligada à construção de uma certa fragilidade de seus protagonistas, ao modo como o realizador isola cada personagem no plano e o deixa funcionar sozinho. Da Lapa carioca dos anos 40 ao sertão cearense do século XXI ("0 céu de Suely"), os temas foram modificados, mas o cinema de Karim continua delicado e vigoroso em seu projeto de nos dar a ver a interação entre o indivíduo e sua circunstância. E é no corpo que está estampada a opressão social e racial que ronda seus protagonistas.

Esse elemento físico, corpóreo, funciona como uma metonímia de toda a proposta do filme. 0 corpo é um instrumento de resposta à incompatibilidade entre o indivíduo e seu espaço.
Será através de seu corpo, na intimidade ou em um lugar público, que o protagonista irá reagir ao mundo e construir seu espaço. 0 corpo é como uma arma de defesa e o próprio sujeito do discurso. Em Madame Satã , o protagonista usa seu corpo para se impor ao espaço e para lá permanecer. Já em $O$ céu de Suely, Hermila precisará de seu corpo para sair de seu espaço. Ou seja: o corpo é um privilegiado ponto de ancoragem a que é possível referir-se para se aprender como sujeito, gerir-se, manipular-se, transformar-se, ultrapassar-se como pessoa ou indivíduo entre os outros.

João Francisco dos Santos se afirma Madame Satã, Hermila vira Suely. Uma política sem teses a comprovar:

[...] que nasce, antes, de uma situação pessoal, de questões individuais que engajam 0 resto da sociedade junto delas: 0 amor homossexual e 0 desencanto com o país em Paixão Nacional, a prostituição como único meio de sair de um lugar que não proporciona a expressão em Rifa-me, a irreconciliável figura de um malandro negro homossexual na primeira metade do século XX em Madame Satã. Essa pequena mudança na estrutura de construção do filme supõe uma grande mudança conceitual na maneira de fazer filmes que toquem em problemas sociais ou políticos. 0 ponto de partida não é mais abstrato como uma ideologia (os ideólogos dirão que não há nada mais concreto do que uma ideologia, o que de certa forma é verdade também) ou um conteúdo programático que se trata de ilustrar ficcionalmente (GARDNIER, 2003).

0 corpo, como descreve o próprio Karim Aïnouz em entrevista aos editores da Cinética, parece 
situado entre a opressão do meio social e 0 exílio existencial.

0 céu de Suely também vem muito a reboque de uma coisa que me aflige demais, que é uma utopia que seja através do corpo e que seja um lugar que eu não sei qual é. Porque eu acho que existe um projeto de utopia hoje, no Brasil e no mundo, que é muito assustador, que é uma utopia religiosa: a possibilidade de um exílio para um lugar sobrenatural. Isso anula qualquer possibilidade de uma utopia física, material, imanente, não-transcendente. Isso para mim é muito importante em todos os meus filmes. Que, na realidade, é uma tentativa de utopia material, por mais que não seja explicada, mas através de seu corpo. Há um desejo meu, que é um pouco programático até, mas é um programático com certa liberdade, de que o espectador, no final dos filmes, tenha uma possibilidade de utopia que ele possa exercitar. Um desejo de imaginar um comportamento, uma experiência, que 0 espectador possa vivenciar e que não seja transcendente (EDUARD0; FELDMAN, 2007).

\section{Apichatpong Weerasethakul}

Já Apichatpong Weerasethakul faz cinema como quem intui um tom, um humor. É um cinema de abstrações, sem perder a emoção. Um cineasta que se credita não pelo tradicional directed by, mas por conceived by. Uma descrição metida à besta, mas justificada. Embora seus filmes sejam experiências conceituais muito rigorosas, existe uma sensualidade que emana de cada um de seus planos. Em longas como Eternamente sua (2002) e Síndrome e um século (2006), parece haver uma certa inocência de encenação, uma simplicidade no registro que se abrem para um outro tipo de fruição. Mal dos trópicos, por exemplo, começa com a movimentação de um destacamento de soldados. Um homem nu atravessa o quadro de um canto ao outro. Imagens do cotidiano de uma cidade ou da vida idílica do campo. Um encontro de conhecidos conversando no trânsito. Só muito aos poucos os personagens ganham nome. Um cinema de atmosfera em que os personagens parecem indestacáveis dos espaços que eles ocupam.

Para entender/ampliar isso, servimo-nos mais uma vez de Merleau-Ponty. A investigação do Ser através da análise da experiência do corpo próprio prossegue em Merleau Ponty com uma revisão mais radical das categorias da metafísica clássica a que dera início. Nesse movimento, o filósofo afirma que o problema ontológico é aquele ao qual se subordinam todos os outros e por isso mesmo a ontologia não pode ser um teísmo, um naturalismo ou um humanismo. Essa posição é reafirmada na última nota de trabalho de seu livro inacabado, $O$ visivel e o invisivel: "trata-se precisamente de mostrar que a filosofia não pode mais pensar segundo esta clivagem: Deus, o homem, as criaturas" (MERLEAU-PONTY, 2003, p. 245).

0 cinema contemporâneo parece acompanhar os desenvolvimentos de Merleau-Ponty e inverte sua força para dentro. 0 cinema de Apichatpong está muito próximo da proposta moderna de um Alain Resnais, por exemplo, quando deshierarquiza passado, futuro e presente; quando recusa uma concepção humanista da natureza e 0 antropomorfismo; mas, ao mesmo tempo, se 
afasta radicalmente dela ao também se recusar a fazer qualquer distinção entre sujeito e objeto.

Ver um filme de Apichatpong Weerasethakul é se tornar parte de um mundo movediço, que se dissolve na descrição de um mundo absolutamente físico, onde todas as coisas se identificam entre si. É um cinema que se inscreve na presença bruta, e assume formas diferentes de fugir do registro da representação para alcançar algum outro tipo de realidade. Weerasethakul parece filmar o mundo num momento que antecede a separação e a organização diferencial de seus objetos, sem fazer distinções entre os termos, "criando um sentimento de fluxo compartilhado. Um cinema que não distingue entre homens, bichos, plantas ou máquinas, e no qual todos dividem um mesmo estado de suspensão" (OLIVEIRA, 2006b).

A descrição de Weerasethakul se aproxima então da proposta de Merleau-Ponty. Se existe um enredo em Mal dos trópicos, ele se resume à tensão da espera de um acontecimento sempre iminente e efetivo apenas a posteriori. 0 casal que se encontra no início de Mal dos Trópicos se separa. Keng precisa voltar para o pelotão, e Tong se afasta em direção ao fundo preto, até se tornar indiscernível. 0 filme se reconstrói todo de novo, agora na forma de um embate apaixonado entre dois homens, dois seres da natureza, desprovidos de qualquer atributo. Keng busca o fantasma de um tigre, encarnação mística de um xamã que "vive nas memórias dos outros" e domina 0 corpo de Tong (ou serão duas outras criaturas interpretadas pelos mesmos atores? Não se sabe). Weerasethakul joga os corpos para dentro da natureza, empreende um movimento centrípeto e puxa tudo para dentro da paisagem e da geografia movediça. 0 sensorial transforma a narrativa e a natureza numa coisa só.

Weerasethakul não identifica 0 "ser" com um dos seres (Deus, o homem ou a Natureza), rejeita pensar segundo esta clivagem entre Deus, o homem e as criaturas. Um filme como Mal dos trópicos não tem como objetivo e efeito espalhar o homem por toda parte, nem mostrar as distâncias entre sujeito e objeto, mas justamente confundi-los, tratando tudo, indiscriminadamente. Olhares, personagens, encontros amorosos e o suor escorrendo pelo corpo são descritos no mesmo nível, na mesma hierarquia narrativa. Uma narrativa física que ressalta a unidade de todas as coisas, uma espécie de cosmos. Não é mais a natureza ou os objetos que se humanizam, mas o próprio homem que perde a sua humanidade.

Não é a toa que Merleau-Ponty fez uma breve incursão na teoria cinematográfica. Para ele, 0 cinema define, em suas linhas gerais, as condições que fazem da sétima arte lugar privilegiado da expressão de uma "visão do mundo" onde contingência, ambiguidade e a concepção do homem como ser-em-situação, informado por uma visão em perspectiva, constituem elementos chave. Este era 0 
argumento por trás de $O$ cinema e a nova

psicologia, conferencia de Merleau-Ponty

proferida no Instituto de Altos Estudos

Cinematográficos (IDHEC) em 13 de março de

1945. Nesse ensaio bastante denso, a perspectiva

fenomenológica e existencial do filósofo ilumina a

"recuperação do visível".

Ao encarar o cinema como um lugar de

organização de novos estímulos sensoriais, de choques e de gozo, nessa defesa ou procura por uma ligação privilegiada do filme com o real, os cinemas de Karim Ainouz, Tsai Ming-Liang e Weerasethakul se aproximam de Merleau-Ponty. No fim de O céu de Suely, Hermila parte sozinha, com um discreto sorriso no rosto, enquanto João vai de moto atrás do ônibus.

Essa imagem apaga a idéia de um corpo se trocando por dinheiro, e revela uma pessoa se transformando em vetor, para atravessar 0 mundo, vivê-lo em diagonal - como ele parece de fato pedir [...] Não seria essa a poesia de um novo indivíduo flutuante, vetorizado, perplexo diante de sua própria experiência de estar-no-mundo (OLIVEIRA, 2006a)?

Num tempo mediado pela tecnologia em que se acena para a ideia de um corpo acoplado às máquinas, este cinema contemporâneo sublinha que 0 corpo não pertence a categorias idealizadas, mas sim a um estado de questionamento de suas potencialidades sensíveis.

Uma boa parte da filosofia fenomenológica ou existencial consiste na admiração dessa inerência do eu ao mundo e ao próximo, em nos descrever esse paradoxo e essa desordem, em fazer ver 0 elo entre 0 indivíduo e 0 universo, entre o indivíduo e os semelhantes, em vez de explicar, como os clássicos, por meio de apelos ao espírito absoluto. Pois o cinema está particularmente apto a tornar manifesta a união do espírito com o corpo, do espírito com o mundo, e a expressão de um dentro do outro (MERLEAU-PONTY, 1983, p. 116).

\section{Referências}

AUMONT, Jacques. 0 cinema e a encenação. Lisboa: Texto \& Grafia, 2008.

BAECQUE, Antoine (org.). Théories du cinéma. Paris: Cahiers du cinema, 2004a.

L'état du cinéma. Paris: Cahiers du cinema, 2004b.

BRAGANÇA, F. "Filmar, hoje, um corpo (em alguns atos)". Cinética, Rio de Janeiro, 2006. Disponível em: $<$ http://www.revistacinetica.com.br/filmarumcorpo. htm>. Acesso em: 20 mar 2010.

CARM0, Paulo Sérgio do. Merleau-Ponty: uma introdução. São Paulo: Educ, 2007.

\section{CHAKALI, Saad. À corps ouvert(s). Cahiers du}

Cinéma, Paris, 2005. Disponível em: <http://www. cahiersducinema.com/article398.html>. Acesso em: 20 mar 2010.

EDUARD0, Cléber; FELDMAN, Ilana. A política do corpo e o corpo político - o cinema de Karim Aïnouz.

Revista Cinética, Rio de Janeiro, 2007. Disponível em: http://www.revistacinetica.com.br/cep/karin_ainouz. htm Acesso em: 20 mar 2010.

GARCIA, Wilton; LYRA, Bernadette (orgs.). Corpo \& imagem. São Paulo: Arte \& Ciência, 2002.

GARDNIER, Ruy ; OLIVEIRA, Luiz C. Jr. et al. Cinema contemporâneo em debate. Contracampo, Rio de Janeiro, n. 78, 2005. Disponível em: <http://www. contracampo.com.br/78/debatecinemacontemporaneo. htm>. Acesso em: 20 mar 2010. 
Mal dos trópicos. Contracampo, Rio de

Janeiro, n. 64, 2004. Disponível em: < http://www. contracampo.com.br/64/tropicalmalady.htm $>$.

Acesso em: 20 mar 2010.

A política íntima de Karim Ainouz.

Contracampo, Rio de Janeiro, n. 50, 2003. Disponível em: <http://www.contracampo.com.br/50/karimainouz. htm>. Acesso em: 20 mar 2010.

GIL, José. Movimento total: o corpo e a dança. Lisboa: Relógio D'água, 2001.

MARQUES, Luisa. 0 corpo que dança e os corpos dos filmes. Contracampo, Rio de Janeiro, n. 91, 2008.

Disponível em: <http://www.contracampo.com.br/91/ artcorpo.htm>. Acesso em: 20 mar 2010.

MERLEAU-PONTY, Maurice. Fenomenologia da percepção. Tradução: Carlos Alberto Ribeiro de Moura. São Paulo: Martins Fontes, 1994.

0 visível e o invisível. Tradução: José Artur Gianotti e Armando Mora d'Oliveira. São Paulo: Perspectiva, 2003.

0 olho e o espírito. Tradução: Marilena

Chauí. São Paulo: Cosac \& Naify, 2004.

0 cinema e a nova psicologia. In: XAVIER,

Ismail (org.). A experiência do cinema. Tradução:

José Lino Grunewald. Rio de Janeiro: Graal, 1983.

p.101-117.

MONASSA, Tatiana. 0 sabor da melancia.

Contracampo, Rio de Janeiro, n. 81, 2006. Disponível

em: <http://www.contracampo.com.br/81/critmelancia. htm >. Acesso em: 20 março 2010.

Cinema mundo. Contracampo, Rio de

Janeiro, n. 66, 2004. Disponível em: <http://www. contracampo.com.br/66/cinemamundotatiana.htm $>$. Acesso em: 20 mar 2010

OLIVEIRA JR., Luiz Carlos. 0 céu de Suely.

Contracampo, Rio de Janeiro, n. 82, 2006a.

Disponível em: <http://www.contracampo.com.br/82/

festoceudesuely.htm>. Acesso em: 20 março 2010.
Síndrome e um século. Contracampo, Rio

de Janeiro, n. 83, 2006b. Disponível em: < http://www. contracampo.com.br/83/mostrasindromeseumseculo. htm>. Acesso em: 20 mar 2010.

SOBCHACK, Vivian. The address of the eye: a phenomenology of film experience. Princeton: Princeton University Press, 1992. 
The body as cogito: a contemporary cinema in the light of Merleau-Ponty

\section{Abstract}

This essay arises from an insight: contemporary cinema is marked by a new transnational wave. A cinema intimately linked to a different look at the body. The body as reflection, as metaphor, as an experimental place for representation. Our hypothesis is that the phenomenology of MerleauPonty provides us with valuable tools to broaden the debate on a cinema that explores a bodily relationship with the world. Our goal is to discuss these issues in brief analyzes of three contemporary filmmakers: Tsai Ming-Liang, A. Weerasethakul and Karim Ainouz.

\section{Keywords}

Contemporary cinema. Body.

Phenomenology. Merleau-Ponty.

\section{El cuerpo como cogito: un cine contemporáneo a la luz de Merleau-Ponty}

\section{Resumen}

Este ensayo surge de una constatación: el cine contemporáneo está marcado por una nueva ola transnacional. Un cine que se encuentra íntimamente asociado a otra manera de ver el cuerpo. El cuerpo como un reflejo, como una metáfora, como un lugar experimental de representación. Nuestra hipótesis es que la fenomenología de Merleau-Ponty nos proporciona herramientas útiles para ampliar el debate sobre un cine que explora una relación corporal con el mundo. Nuestro objetivo es discutir estos temas en breves análisis de tres cineastas contemporáneos: Tsai Ming-Liang, A. Weerasethakul y Karim Ainouz.

\section{Palabras clave}

Cine contemporáneo. Cuerpo.

Fenomenología. Merleau-Ponty. 


\section{Expediente}

A revista E-Compós é a publicação científica em formato eletrônico da Associação Nacional dos Programas de Pós-Graduação em Comunicação (Compós). Lançada em 2004, tem como principal finalidade difundir a produção acadêmica de pesquisadores da área de Comunicação, inseridos em instituições do Brasil e do exterior.

\section{E-COMPÓS I www.e-compos.org.br I E-ISSN 1808-2599}

Revista da Associação Nacional dos Programas de Pós-Graduação em Comunicação. Brasília, v.13, n.1, jan./abr. 2010.

A identificação das edições, a partir de 2008, passa a ser volume anual com três números.

\section{CONSELHO EDITORIAL}

Afonso Albuquerque

Universidade Federal Fluminense, Brasil

Alberto Carlos Augusto Klein

Universidade Estadual de Londrina, Brasil

Alex Fernando Teixeira Primo

Universidade Federal do Rio Grande do Sul, Brasil

Alfredo Vizeu

Universidade Federal de Pernambuco, Brasil

Ana Carolina Damboriarena Escosteguy

Pontifícia Universidade Católica do Rio Grande do Sul, Brasil

Ana Silvia Lopes Davi Médola

Universidade Estadual Paulista, Brasil

André Luiz Martins Lemos

Universidade Federal da Bahia, Brasil

Ângela Freire Prysthon

Universidade Federal de Pernambuco, Brasil

Antônio Fausto Neto

Universidade do Vale do Rio dos Sinos, Brasil

Antonio Carlos Hohlfeldt

Pontifícia Universidade Católica do Rio Grande do Sul, Brasil

Arlindo Ribeiro Machado

Universidade de São Paulo, Brasil

César Geraldo Guimarães

Universidade Federal de Minas Gerais, Brasil

Cristiane Freitas Gutfreind

Pontifícia Universidade Católica do Rio Grande do Sul, Brasil

Denilson Lopes

Universidade Federal do Rio de Janeiro, Brasil

Eduardo Peñuela Cañizal

Universidade Paulista, Brasil

Erick Felinto de Oliveira

Universidade do Estado do Rio de Janeiro, Brasil

Francisco Menezes Martins

Universidade Tuiuti do Paraná, Brasil

Gelson Santana

Universidade Anhembi/Morumbi, Brasil

Goiamérico Felício

Universidade Federal de Goiás, Brasil

Hector Ospina

Universidad de Manizales, Colômbia

Herom Vargas

Universidade Municipal de São Caetano do Sul, Brasil

leda Tucherman

Universidade Federal do Rio de Janeiro, Brasil

Itania Maria Mota Gomes

Universidade Federal da Bahia, Brasil

Janice Caiafa

Universidade Federal do Rio de Janeiro, Brasil

Jeder Silveira Janotti Junior

Universidade Federal da Bahia, Brasil
João Freire Filho

Universidade Federal do Rio de Janeiro, Brasil

John DH Downing

University of Texas at Austin, Estados Unidos

José Luiz Aidar Prado

Pontifícia Universidade Católica de São Paulo, Brasil

José Luiz Warren Jardim Gomes Braga

Universidade do Vale do Rio dos Sinos, Brasil

Juremir Machado da Silva

Pontifícia Universidade Católica do Rio Grande do Sul, Brasil

Lorraine Leu

University of Bristol, Grã-Bretanha

Luiz Claudio Martino

Universidade de Brasília, Brasil

Maria Immacolata Vassallo de Lopes

Universidade de São Paulo, Brasil

Maria Lucia Santaella

Pontifícia Universidade Católica de São Paulo, Brasil

Mauro Pereira Porto

Tulane University, Estados Unidos

Muniz Sodre de Araujo Cabra

Universidade Federal do Rio de Janeiro, Brasil

Nilda Aparecida Jacks

Universidade Federal do Rio Grande do Sul, Brasil

Paulo Roberto Gibaldi Vaz

Universidade Federal do Rio de Janeiro, Brasil

Renato Cordeiro Gomes

Pontifícia Universidade Católica do Rio de Janeiro, Brasil

Ronaldo George Helal

Universidade do Estado do Rio de Janeiro, Brasil

Rosana de Lima Soares

Universidade de São Paulo, Brasil

Rossana Reguillo

Instituto Tecnológico y de Estudios Superiores do Occidente, México

Rousiley Celi Moreira Maia

Universidade Federal de Minas Gerais, Brasil

Samuel Paiva

Universidade Federal de São Carlos, Brasil

Sebastião Albano

Universidade Federal do Rio Grande do Norte, Brasil

Sebastião Carlos de Morais Squirra

Universidade Metodista de São Paulo, Brasil

Simone Maria Andrade Pereira de Sá

Universidade Federal Fluminense, Brasi

Suzete Venturelli

Universidade de Brasília, Brasil

Valério Cruz Brittos

Universidade do Vale do Rio dos Sinos, Brasil

Veneza Mayora Ronsini

Universidade Federal de Santa Maria, Brasil

Vera Regina Veiga França

Universidade Federal de Minas Gerais, Brasil

\section{COMISSÃO EDITORIAL}

Felipe da Costa Trotta I Universidade Federal de Pernambuco, Brasil Rose Melo Rocha I Escola Superior de Propaganda e Marketing, Brasil CONSULTORES AD HOC

João Maia I Universidade do Estado do Rio de Janeiro, Brasil Sandra Gonçalves I Universidade Federal do Rio Grande do Sul, Brasil Mayra Rodrigues Gomes I Universidade de São Paulo, Brasil Gisela Castro I Escola Superior de Propaganda e Marketing, Brasil João Carrascoza I Escola Superior de Propaganda e Marketing, Brasil Luciana Pellin Mielniczuk I Universidade Federal de Santa Maria, Brasil Irene de Araújo Machado I Universidade de São Paulo, Brasil Hermilio Pereira dos Santos Filho I Pontifícia Universidade Católica, Brasil Benjamim Picado I Universidade Federal Fluminense, Brasil Maria Apaecida Baccega I Escola Superior de Propaganda e Marketing, Brasil Rogério Ferraraz I Universidade Anhembi Morumbi, Brasil

Bruno Souza Leal I Universidade Federal de Minas Gerais, Brasi REVISÃO DE TEXTO E TRADUÇÃo I Everton Cardoso EDITORAÇ̃o ELETRÔNICA I Roka Estúdio
COMPóS I www.compos.org.br

Associação Nacional dos Programas de Pós-Graduação em Comunicação

Presidente

Itania Maria Mota Gomes

Universidade Federal da Bahia, Brasil

itania@ufba.br

Vice-presidente

Julio Pinto

Pontifícia Universidade Católica de Minas Gerais, Brasil juliopinto@pucminas.br

Secretária-Geral

Ana Carolina Escosteguy

Pontifícia Universidade Católica do Rio Grande do Sul, Brasil carolad@pucrs.br 